\title{
FUNDAMENTOS DA DETEÇÃO AUTOMÁTICA DE INCÊNDIOS EM EDIFÍCIOS
}

\section{PARTE 2.}

\section{Detetores automáticos}

Conforme referido no parágrafo 3 do artigo publicado no número 17 da revista Neutro à Terra, existem no mercado, diversos tipos de detetores automáticos de incêndio.

Os detetores de incêndio são normalmente concebidos para detetar uma ou mais características de um incêndio: fumo, calor, radiação (chama) e outros produtos de combustão.

Cada tipo de detetor responde com rapidez diferente aos diferentes tipos de incêndio.

De entre os diversos tipos de detetores, os detetores de fumos e de temperatura, são os mais utilizados, permitindo dar resposta à generalidade das necessidades de deteção.

Para situações particulares de deteção são usados outro tipo de detetores como os detetores de chamas e os detetores lineares.

\section{i. Detetores de fumos (Óticos)}

Os detetores óticos de fumo são rápidos na deteção de um fogo e têm uma resposta suficientemente vasta para permitir uma utilização generalizada.

Respondem a fumo visível, sendo bom para fogos onde não há chamas, como é o caso de fogos com tecidos, mobília, móveis, etc.. Não detetam os produtos de combustão limpa de líquidos inflamáveis (tal como o álcool).

São ideais para espaços amplos, onde a presença de fumo é mais facilmente detetada do que a elevação de temperatura, pois o calor dissipa-se mais facilmente.
Os detetores de fumos não são apropriados para locais onde se verifique a permanente existência de fumos, vapor ou pó, como é o caso de garagens, cozinhas e industrias transformadoras de madeiras, devido à possibilidade de ocorrência de falsos alarmes.

Os detetores óticos de fumos podem ter como principio de funcionamento a absorção de luz ou a dispersão de luz.

A figura 1 ilustra o principio de funcionamento de um detetor ótico de fumos de absorção de luz.

Sem fumo

Camera de análise

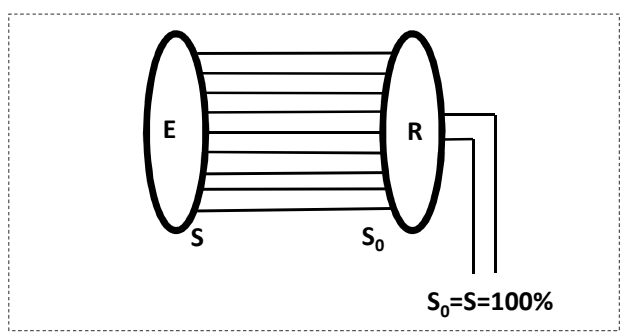

Com fumo

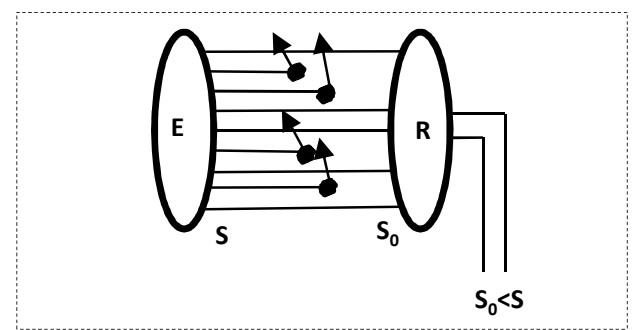

E: Emissor (Fonte de luz)

R: recetor (Fotocélula)

S: Sinal

Figura 1. Principio de funcionamento de um detetor ótico de fumos de absorção de luz 
A figura 2 ilustra o principio de funcionamento de um detetor ótico de fumos de dispersão de luz.

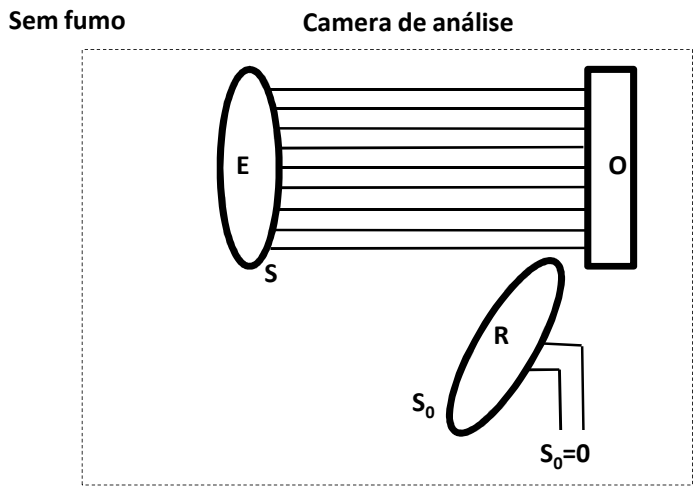

Com fumo

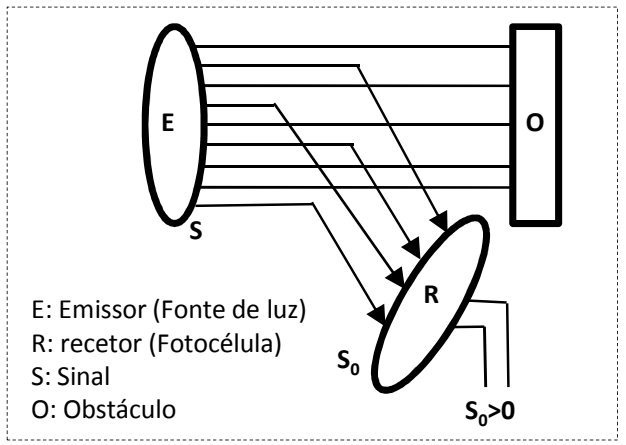

Figura 2. Principio de funcionamento de um detetor ótico de fumos de dispersão de luz

A figura 3 mostra uma imagem de um detetor ótico de fumos.

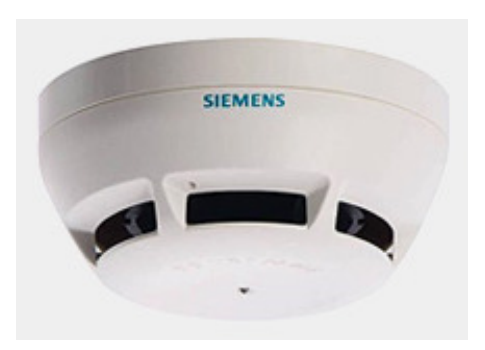

Figura 3. Detetor ótico de fumos [SIEMENS]

\section{ii. Detetores de feixe}

Os detetores de feixe, também designados como detetores lineares de fumos, são uma solução muito interessante para proteção contra incêndios em locais interiores, abertos e com elevadas dimensões.
São robustos, de fácil instalação, de manutenção reduzida, têm uma fiabilidade elevada (reduzida probabilidade de ocorrência de falsos alarmes) e, promovem uma deteção da situação de alarme muito rápida, o que num sistema automático de segurança, são aspetos fundamentais.

Como situações onde podem ser empregues os detetores lineares de fumos, podem-se referir:

- Grandes espaços com tetos altos de difícil acesso para manutenção;

- Empresas de reciclagem;

- Edifícios históricos, igrejas, museus;

- Naves industriais, armazéns;

- Centros comerciais;

- Corredores, $\ldots$

Um detetor de feixe consiste fundamentalmente num emissor de fluxo luminoso, visível ou invisível, cuja intensidade é medida por uma célula: o recetor. $\mathrm{O}$ recetor focaliza o fluxo recebido e oferece características de vigilância.

Os fumos emanados de um foco vão atenuar o fluxo do emissor, provocando assim uma modificação das características do fluxo recebido pelo recetor.

A informação de alarme resulta de um valor prédeterminado da atenuação do fluxo luminoso.

A figura 4 mostra o principio de funcionamento de um detetor de feixe.

Emissor de luz
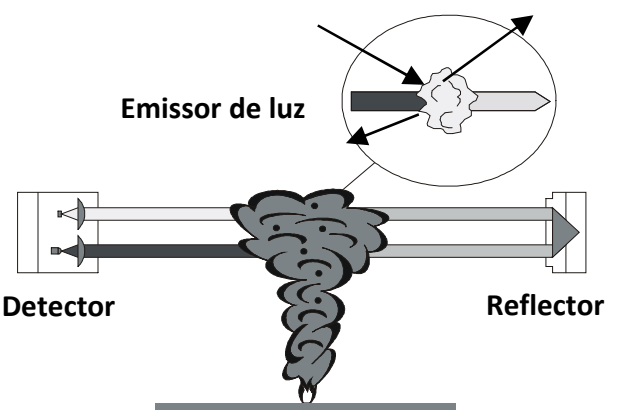

Figura 4. Principio geral de funcionamento de um detetor de feixe 
A figura 5 mostra uma imagem de um detetor de feixe, constituído por um emissor/recetor e um espelho refletor.

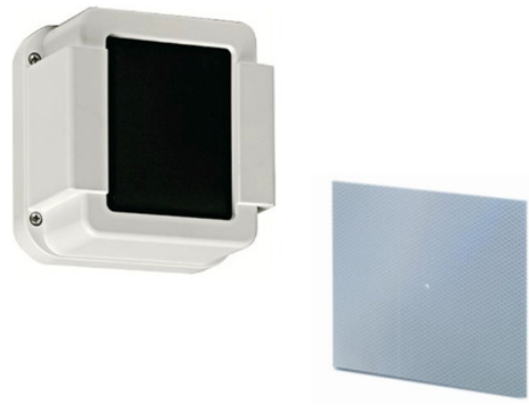

Figura 5. Detetor de feixe [SIEMENS]

\section{iii. Câmaras de aspiração}

Utilizam um sistema de aspiração elétrico e uma rede de tubagem para recolher ar ambiente da área protegida e para transportar a amostra a um sensor que pode estar colocado fora dessa área.

A tubagem de recolha tem normalmente vários orifícios, e a densidade do fumo no sensor será o valor médio da densidade do fumo de todos os orifícios da tubagem.

O ar ambiente dos locais de risco, vigiados por este processo, é controlado numa câmara intercalada na rede, onde está incorporado um detetor de fumos.

A figura 6 mostra uma imagem de um sistema de deteção de incêndios por aspiração.

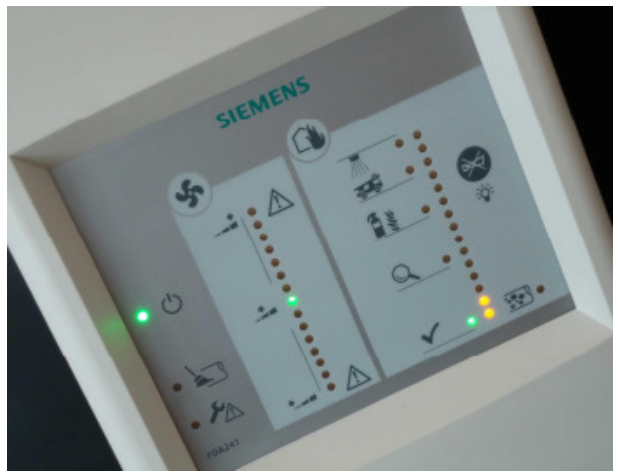

Figura 6. Sistema de deteção de incêndios por aspiração

[SIEMENS]

\section{iv. Detetores de temperatura (Térmicos)}

São geralmente considerados como os menos sensíveis dos vários tipos de detetores disponíveis.

Em geral um detetor de temperatura tem uma resposta mais lenta do que os detetores de fumos.

Para incêndios que produzam um rápido aumento de temperatura e muito pouco fumo pode acionar um detetor de temperatura antes de acionar um detetor de fumo.

A deteção é baseada em termistências, cuja resistência elétrica varia fortemente quando a temperatura sobe.

A alteração da corrente elétrica que daí resulta dará o sinal.

A figura 7 mostra o principio geral de funcionamento de um detetor de temperatura.

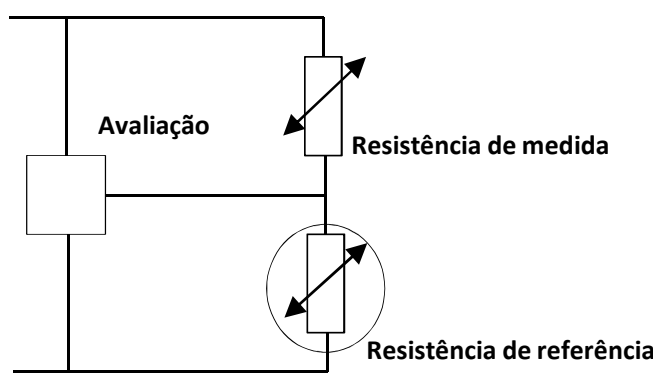

Figura 7. Principio geral de funcionamento de um detetor de temperatura

Os detetores de temperatura fixa são mais adequados em locais onde se prevê que a temperatura ambiente possa variar rapidamente em curtos espaços de tempo, enquanto que os detetores termovelocimétricos são mais adequados em locais onde as temperaturas ambientes são baixas ou variam lentamente. 
A figura 8 mostra uma imagem de um detetor de temperatura.

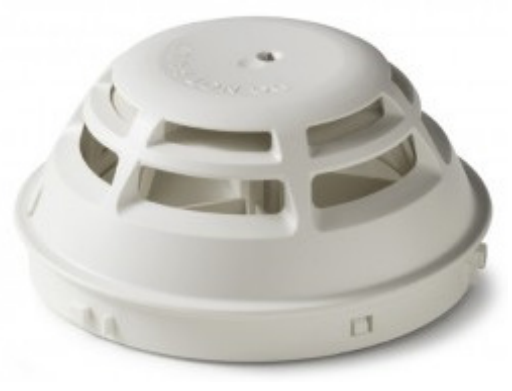

Figura 6. Detetor de temperatura [SIEMENS]

\section{v. Detetores lineares de calor}

Os detetores lineares de calor, são uma solução muito interessante, para proteção contra incêndios em locais exteriores e em locais nos quais se possa verificar a presença de agentes químicos, corrosão, níveis de humidade e poeira elevados e altas temperaturas.

Como situações onde podem ser empregues os detetores lineares de temperatura, pode-se referir:

- Túneis;

- Minas;

- Parques de estacionamento;

- Estações ferroviárias, terminais de passageiros, corredores de ligação;

- Depósitos de líquidos e gases combustíveis

- Estações de abastecimento de combustível;

- Locais ATEX;

- Galerias e caminhos de cabos;

- Fábricas químicas, farmacêutica, tintas,...

Os detetores lineares de calor são robustos, de fácil instalação, de manutenção reduzida, têm uma fiabilidade elevada (reduzida probabilidade de ocorrência de falsos alarmes) e promovem uma deteção da situação de alarme muito rápida, além de permitir indicar, na unidade de controlo, qual o ponto de alarme ao longo do seu comprimento o que, num sistema automático de segurança, são aspetos fundamentais.
Existem diversas tecnologias dos detetores lineares de calor:

\section{- Deteção linear de temperatura por variação de pressão}

Uma das tecnologias baseia-se na alteração da resistência de um condutor elétrico causada por uma variação de temperatura.

Num cabo sensor, constituído por quatros condutores, cada um dos seus condutores está rodeado por um material com um coeficiente de temperatura negativo e envolvido numa cobertura externa resistente ao calor.

Dois condutores estão ligados à extremidade do cabo do sensor para criar dois loops.

A extremidade do cabo do sensor encontra-se, assim, hermeticamente selada.

Ambos os loops são continuamente monitorizados.

Em caso de interrupção ou curto-circuito, a unidade de controlo gera uma mensagem de avaria ou alarme.

Se a temperatura subir, a resistência elétrica entre os dois loops altera-se.

A unidade de controlo deteta esta alteração e sinaliza o alarme se a temperatura de resposta definida for excedida.

A figura 8 mostra uma unidade de controlo do sistema anteriormente descrito.

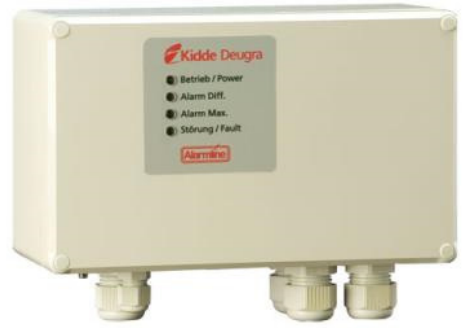

Figura 8. Detetor Linear de Calor (Bosch) 


\section{- Deteção linear de temperatura por variação de resistência}

Consiste na monitorização da expansão volumétrica de um gás sujeito a aquecimento e no aumento correspondente da pressão num sistema pneumaticamente estanque.

O detetor de calor é composto, genericamente, por um tubo sensor e uma caixa de deteção (com unidade de controlo).

O sensor de pressão mede continuamente a pressão no tubo sensor e envia os sinais para monitorização pela unidade de controlo.

Se a pressão no tubo sensor subir rapidamente, devido a um aumento de temperatura, a unidade de controlo sinaliza o alarme.

\section{vi. Detetores de chamas}

Os detetores de chamas detetam a radiação emitida pelo incêndio, podendo ter como principio de funcionamento a deteção da radiação ultravioleta, a radiação infravermelha, ou a combinação das duas.

São inadequados para detetar incêndios de combustão lenta, pelo que não devem ser considerados como de utilização generalizada. Podem contudo responder a um incêndio com chama, como por exemplo envolvendo líquidos inflamáveis, mais rapidamente do que detetores de temperatura ou de fumo.

O espectro da radiação da maioria dos materiais inflamáveis tem uma banda suficientemente larga para permitir que a chama seja detetada por qualquer tipo de detetor de chamas, mas com alguns materiais (tal como materiais inorgânicos) pode ser necessário escolher o detetor de chamas capaz de responder a partes específicas do espectro dos comprimentos de onda.

Os detetores de chamas são particularmente adequados para ser utilizados em situações tais como a vigilância geral de grandes áreas abertas em armazéns ou depósitos de madeiras, ou para a vigilância local de áreas criticas em que os incêndios com chama se possam propagar rapidamente, p. ex. em bombas, válvulas ou condutas contendo combustíveis líquidos, ou áreas com materiais combustíveis dispostos em finos planos de orientação vertical, tais como painéis ou pinturas a óleo.

Os detetores de chamas só deverão ser utilizados caso haja uma linha de vista para a área a ser protegida.

A figura 9 mostra um exemplo de um detetor de chama.

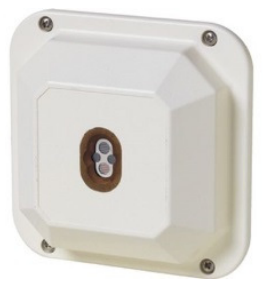

Figura 9. Detetor de chama (SIEMENS)

\section{i. Detetores multisensores}

Os detetores multisensores combinam um ou mais tipos de detetores (fumo/temperatura/chama/monóxido de carbono) e processam os sinais de cada tipo utilizando cálculos matemáticos.

Assim pode-se obter uma melhor distinção entre alarmes reais e intempestivos.

\section{Bibliografia:}

[1] Regime jurídico da segurança contra incêndios em edifícios, Decreto-Lei n. 220/2008 de 12 de Novembro.

[2] Regulamento Técnico de Segurança Contra Incêndio em Edifícios (SCIE), Portaria n. 1532/2008 de 29 de Dezembro.

[3] Segurança Contra Incêndio em Edifícios, Notas técnicas, Autoridade Nacional da Proteção Civil (ANPC).

[4] Norma EN 54 - Sistemas de deteção e de alarme de incêndio (Série).

[5] Deteção e extinção de incêndio em DataCenter, Rui Miguel Barbosa Neto, 2014, ISEP. (Dissertação de mestrado em Engenharia Eletrotécnica - Sistemas Elétricos de Energia). 